\title{
WAVE - INDUCED DEVICES FOR THE OXYGENATION OF DEEP LAYER: A PHYSICAL INVESTIGATION
}

\author{
Alessandro Antonini' ${ }^{1}$, Maria Gabriella Gaeta ${ }^{2}$, Alberto Lamberti ${ }^{1}$ \\ No other environmental variable of ecological importance to estuarine and coastal marine ecosystems around the \\ world has changed so drastically, in such a short period of time, as dissolved oxygen. Coastal surveys in United States \\ and Europe found that a staggering $78 \%$ of the assessed continental U.S. coastal area and approximately $65 \%$ of \\ Europe's Atlantic coast exhibit symptoms of eutrophication. The $65 \%$ of the coasts counted by Diaz does not take \\ into account inland seas like the Adriatic or Baltic Seas but also for these, eutrophication and consequently anoxia are \\ common problems. In the present study a simple and economic device is proposed to enhance vertical mixing \\ processes and to induce aeration of deep water by pumping of oxygen-rich surface water downwards to a desired \\ depth around the halocline. The hydrodynamic parameters of the device are estimated through free oscillation tests. \\ Preliminary values of the downward water flux velocity inside the device and the movements of the floater under the \\ action of 4 regular waves, characterizing of the wave climate in the Nord Adriatic Sea, are estimated.
}

Keywords: anoxia, oxygenation, physical modeling, wave energy, stratification.

\section{INTRODUCTION}

The term eutrophication refers to an excessive enrichment of waters in nutrients, and its associated adverse biological effects (European Environmental Agency, 1994). Cultural eutrophication, which results from human activity, may negatively affect marine ecosystems, increasing the occurrence of massive benthos and fish mortality, loss of diversity, poisoning episodes which also cause human illness, and mucilage production (e.g. Smayda 1990; Viviani 1992; Vollenweider et al. 1992; Cattani and Vitali 1995; Degobbis et al. 1995).

The Northern Adriatic Sea is the northernmost area of the Mediterranean Sea. It is characterized by shallow waters (maximum depth is around $70 \mathrm{~m}$ ) and considerable freshwater input mainly coming from the river Po, the largest Italian river (Sangiorgi et al. 2003).

Water circulation is dominated by a counter-clockwise flow, induced by thermohaline factors and Coriolis acceleration, which confines the nutrient-rich freshwaters to the western coastal regions (Zavatarelli et al. 1998).

Benthic flux measurements indicate that recycled nutrients from the sea bottom may be comparable to the input of nutrients from river Po (Giordani et al. 1992). Consequently, massive diatom and dinoflagellate blooms, "red tides" sometimes associated with toxicity episodes, are well known along the northwestern Adriatic coast (Boni et al. 1986; 2000).

Anthropogenic loading of rivers entering the north-western Adriatic Sea has considerably increased nutrient input to the system during the late 20th century, especially between 1968 and 1980 (Marchetti et al. 1989). A major fraction of the productivity in surface waters reaches the sea floor (Giordani et al. 1992) and anoxic or near anoxic events frequently occur in bottom waters, especially in late summer and autumn as a consequence of high downward organic fluxes, microbial decay and thermal stratification (Degobbis 1989; Zavatarelli et al. 1998).

The purpose of the present work is to investigate the possibilities for a simple and economic device to enhance vertical mixing processes and to induce aeration in deep waters by downward pumping the oxygen rich surface waters.

\section{OBJECTIVES}

The physical principle of the tested floating device is the capacity to enhance vertical mixing processes and to induce aeration of deep water by pumping of oxygen-rich surface water downwards to a desired depth around the halocline. The floater should collect incoming waves into a reservoir floating on the sea. The overtopping of water yields a higher head in the reservoir, which in turn induces a water flux downwards.

The main objectives proposed by the paper are the following:

- proof of concept;

- hydrodynamic characterization of the model device;

\footnotetext{
${ }^{1}$ DICAM, University of Bologna, Via Risorgimento 2, Bologna, 40136, Italy. alessandro.antonini2/alberto.lamberti@unibo.it

${ }^{2}$ CIRI, Fluid dynamics Unit, University of Bologna, Via del Lazzaretto 15/5, Bologna, 40134, Italy. g.gaeta@unibo.it
} 
- evaluation of the displacements of the device under almost calm seas (condition of normal operation) and under extreme waves;

- measurements of the mean velocity of the downward flow inside the device.

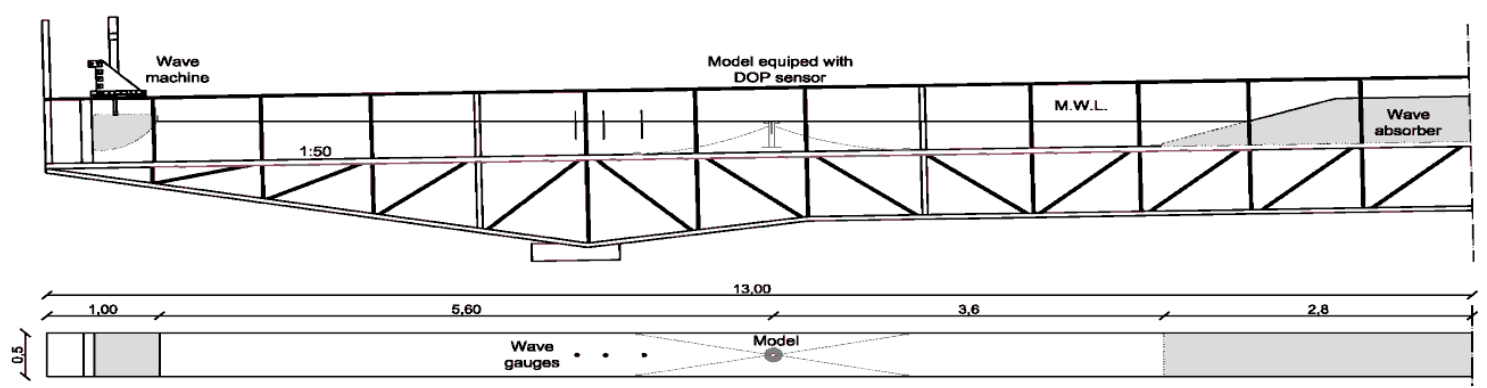

Figure 1. Test set-up (all values are in meters): longitudinal (top) and aerial (bottom) views.

\section{EXPERIMENTAL SET-UP}

\section{Description of the laboratory set-up and models}

The experiments are carried out in the wave flume of the University of Bologna, characterized by dimensions: length $15 \mathrm{~m}$, width $0.5 \mathrm{~m}$ and depth $0.7 \mathrm{~m}$. Figure 1 shows the experimental set-up. A vertical piston-type wave paddle generates waves at one end of the wave flume, while a passive wave absorber is installed at the other end.

Two types of the device (Figure 2) are built in 1:16 scale. Three different parts constitute the device: the truncated conical floater at the top, the stabilizing ring at the bottom and the tube that connects the floater and the ring.

The first tested model is completely rigid ( $\mathrm{R}$ ) with the tube built by plexiglas (right), whereas the second model is flexible (F) the tube being made of a plastics film (left). In both models the duct diameter is $0.05 \mathrm{~m}$ and its length is equal to $0.30 \mathrm{~m}$.

Two mooring systems are investigated: the first one is composed by four chains $(\mathrm{CH})$ hooked up to the bottom part of the floater, whereas the second system is made with two pretensioned nylon cables (CA).

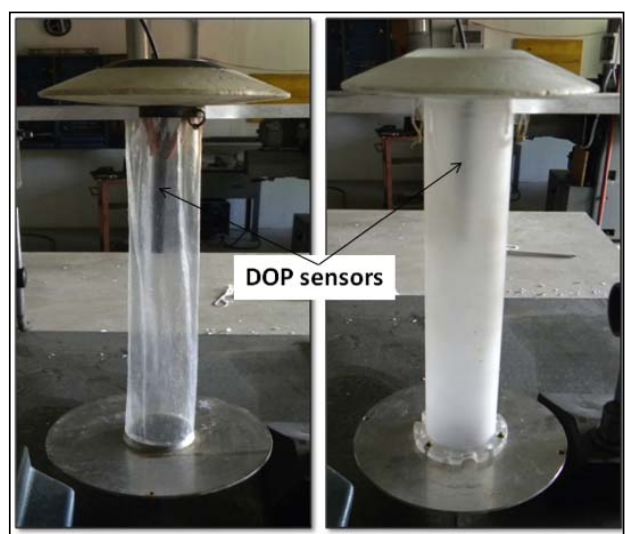

Figure 2. Tested devices: flexible (left) and rigid (right) types. DOP sensors are mounted into the tubes.

One Doppler Profiler (DOP) sensor is mounted in the center of the duct to measure the velocity of the downward flux. Vertical circulation cells are estimated by injecting dye and video-recording the water flow in the device; the floater displacements are also evaluated from the videos. Records are obtained at 30 fps.

Records are analyzed through an image processing procedure, where the two extreme points on the floater (the blue points in Figure 3) and the water surface position are identified in the image. The result consists of a series of points in space and time: the time displacement and elliptical trajectory of the floater is therefore by phase averaging positions in different wave cycles. 


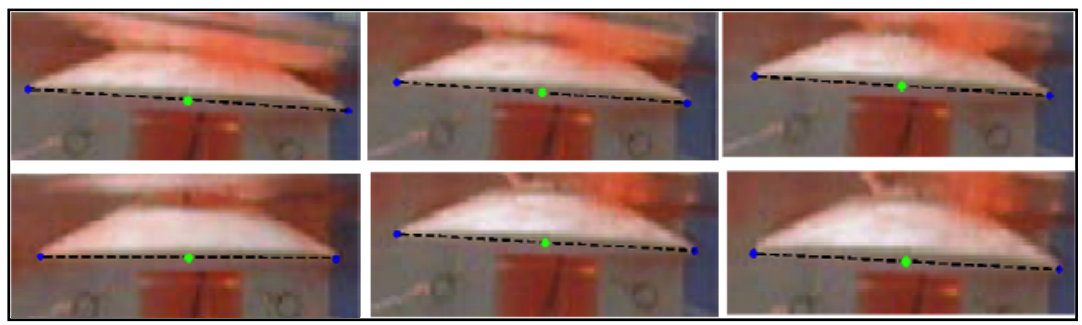

Figure 3 Sequence of the analyzed frames for device $\mathbf{R}$.

The influence of the floater emergence is also investigated: two different levels of buoyancy (i.e. the floater freeboard with respect to swl) equal to $\mathrm{c}_{1}=0.5 \mathrm{~cm}$ and $\mathrm{c}_{2}=0.8 \mathrm{~cm}$ are tested.

\section{Wave conditions}

Four different regular waves are generated in the wave flume, in order to reproduce according to Froude scaling law typical sea states occurring on the Northern Adriatic Sea. The wave climate is identified by means of the analysis of the data coming from the Nausicaa Buoy, located offshore the Cesenatico coast at a depth of $10 \mathrm{~m}$. 4 different waves are derived and reported in Table 1: the almost calm $(\mathrm{Cc})$, the ordinary state generated by seaward wind $(\mathrm{Tc})$, the extreme $(\mathrm{Te})$ and the ordinary states generated by southeast wind $(\mathrm{Sc})$.

Although waves are recorded at gauges, water surface elevation is also identified through video analysis: this was found to be the simplest technique to synchronize the device displacement and the incoming wave oscillation.

At the model scale, the target wave height $\mathrm{H}_{\mathrm{s}}$ varies between 1.00 and $10.00 \mathrm{~cm}$, with a mean period $\mathrm{T}_{\mathrm{m}}$ ranging between 0.68 and $1.15 \mathrm{~s}$, corresponding to $1-5 \%$ wave steepness. Target wave conditions are generated satisfactorily, although slight deviations between recorded $\left(\mathrm{H}_{\mathrm{s}}, \mathrm{T}_{\mathrm{m}}\right)$ and target $\left(\mathrm{H}_{\mathrm{sT}}, \mathrm{T}_{\mathrm{mT}}\right)$ values do occur.

\begin{tabular}{|c|c|c|c|c|}
\hline \multicolumn{5}{|c|}{ Table 1. Experimental conditions } \\
\hline $\begin{array}{c}\text { Waves } \\
\text { states }\end{array}$ & $\mathbf{H}_{\mathrm{s}, \mathrm{T}} \mathbf{( \mathbf { c m } )}$ & $\mathbf{T}_{\mathrm{m}, \mathrm{T}} \mathbf{( s )}$ & $\mathbf{H}_{\mathrm{s}} \mathbf{( c m )}$ & $\mathbf{T}_{\mathrm{m}} \mathbf{( s )}$ \\
\hline $\mathrm{Cc}$ & 1.00 & 0.72 & 1.08 & 0.7 \\
\hline $\mathrm{Tc}$ & 3.00 & 0.68 & 1.82 & 0.7 \\
\hline $\mathrm{Te}$ & 10.00 & 1.15 & 10.20 & 1.1 \\
\hline $\mathrm{Sc}$ & 5.00 & 1.06 & 5.66 & 1.0 \\
\hline
\end{tabular}

At the device location, the still water depth is imposed equal to $0.40 \mathrm{~m}$.

Totally, 2 devices ( $\mathrm{R}$ and $\mathrm{F}), 2$ different types of mooring ( $\mathrm{CH}$ and $\mathrm{CA}), 2$ floater submergences $\left(\mathrm{c}_{1}\right.$ and $\left.\mathrm{c}_{2}\right), 4$ waves $(\mathrm{Cc}, \mathrm{Tc}, \mathrm{Te}, \mathrm{Sc})$ are studied, for a total of 32 tests.

\section{PROOF OF CONCEPT}

The physical principle of the tested devices is the capacity to mix waters, pumping superficial water masses downwards: the floater collects part of the incoming wave crest into the reservoir and the higher head induces water flux through the pipe in the downward direction.

At the prototype scale, the pipe will be several meters long, roughly going from the surface to the sea bottom where the oxygen is required. Such a long pipe will have distributed losses due to its length and roughness, as well as inlet and outlet losses. The issue of difference in water density will be also an aspect to account for.

The device is designed to operate outside the surf zones, but the installation location in terms of depth and distance from the coastline is closely related to local conditions of anoxia development. The North Adriatic Sea receives abundant freshwater runoff from the surrounding lands and the salinity of 
the upper layer is not high. Figure 4 shows a typical density anomaly for the North Adriatic Sea during summer, when the maximum water stratification occurs.

Data of salinity and temperature profile (Artegiani 1996) are used in order to estimate differences in water density (Fofonoff et al. 1983) during the summer.

The pressure difference $\Delta p$, necessary to let water circulate is estimated by Eq. (1):

$$
\Delta p=\oint \gamma \cdot d z
$$

where in the duct the water has the superficial density and outside the duct the water stratified.

For instance, in case of a $50.00 \mathrm{~m}$ long pipe with a diameter of $0.50 \mathrm{~m}$, the required head $\Delta \mathrm{h}_{\gamma}$ is estimated to be equal to $0.068 \mathrm{~m}$, while for a $15 \mathrm{~m}$ depth, more frequent in anoxic areas along the Northern Adriatic Sea, the $\Delta \mathrm{h}_{\gamma}$ value is equal to $0.002 \mathrm{~m}$.

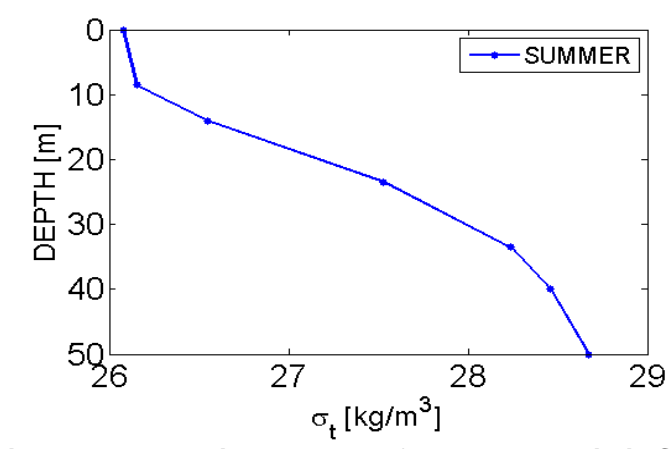

Figure 4. Characteristic summer density anomaly of the North Adriatic Sea (Artegiani 1996 ).

\section{RESULTS}

\section{Free oscillation tests}

In preliminary tests performed in still water, the device is released from an initial position far from its equilibrium. Hence, the device undergoes a damped free oscillation motion. For these tests, both the devices ( $\mathrm{R}$ and $\mathrm{F}$ ) and both the mooring systems ( $\mathrm{CH}$ and $\mathrm{CA}$ ) are tested. In addition, to evaluate the influence of the mooring systems, a free oscillation test without any chains or cables is also performed.

The relevant hydrodynamic parameters such as natural period $(\mathrm{T} \propto \sqrt{m / k})$ and damping ratio $(\zeta \propto c / \sqrt{m \cdot k})$ are derived by using the image records and the free surface oscillations.

The damping coefficient is calculated using logarithmic decrement method (Czolczynski 2003) as:

$$
\begin{aligned}
& \Delta=\ln \left(\frac{H_{t}}{H_{t+T}}\right) \\
& \zeta=\frac{\Delta}{\sqrt{4 \pi^{2}+\Delta^{2}}}
\end{aligned}
$$

where $\Delta$ is the logarithmic decrement $\mathrm{H}_{\mathrm{t}}$ and $\mathrm{H}_{\mathrm{t}+\mathrm{T}}$ are the correspondent amplitudes at instant $\mathrm{t}$ and $\mathrm{t}+\mathrm{T}$, where $\mathrm{T}$ is the natural period of free oscillation.

In Figure 5, time evolution of the vertical displacements for the oscillation tests is shown for the rigid and the flexible devices and the difference mooring systems are also compared. Table 2 reports the estimated values for the natural period and the damping coefficients.

For the rigid device,

- the mooring system has a significant effect on the device response. The chains, with bigger mass, give a lower boost to the floater than the cables, the floater sinks and the floating section is reduced; therefore the natural period is longer in the device anchored with chains;

-the damping ratio shows a slight increase when mooring is changed from chains (around 0.08) to cables (around 0.10). 

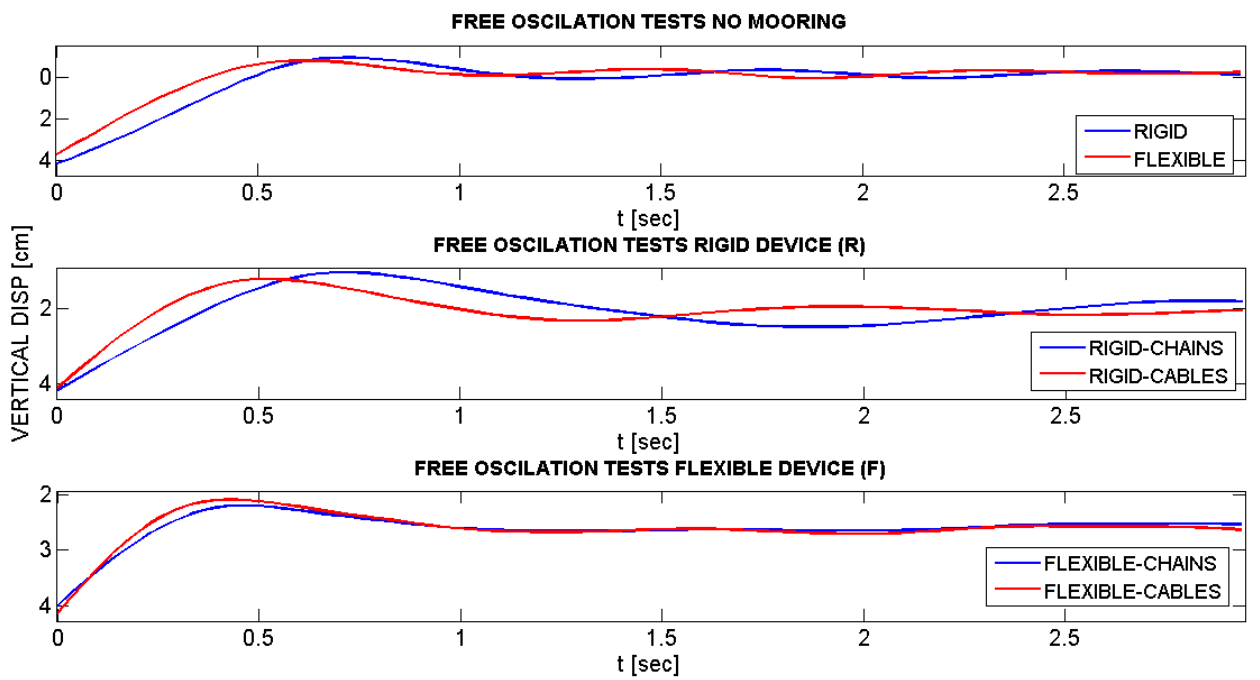

Figure 5. Results of the free oscillation tests: vertical displacements in time for rigid and flexible devices.

For the flexible device, the results are harder to be interpreted:

- the heave is almost independent by the mooring systems, especially for the natural period that presents no relevant variations with the mooring systems. A second natural period is also evident in the results; this could be explained by the mechanical characteristics of the device. The flexible duct is less massive and more compliant than the rigid one an can not contrast compression; the compliance of the duct generates more degrees of freedom and natural periods, and the nonlinear elastic behavior highly distorted oscillations;

- the damping ratio is slightly affected by the mooring systems and their different stiffness, as well as for the rigid device.

\begin{tabular}{|c|c|c|}
\hline \multicolumn{3}{|c|}{ Table 2. Results coming from free oscillation tests } \\
\hline Device / Mooring systems & \multirow{2}{*}{$\begin{array}{c}\text { Natural period } \\
\text { (sec) }\end{array}$} & $\begin{array}{c}\text { Damping } \\
\text { factor }\end{array}$ \\
Rigid - no moorings & \multicolumn{2}{|c}{} \\
Rigid - Chains & 0.94 & 0.115 \\
\hline Rigid - Cables & 2.13 & 0.083 \\
\hline Flexible - no moorings & 1.22 & 0.109 \\
\hline Flexible - Chains & 0.85 & 0.089 \\
\hline Flexibles - Cables & 1.06 & 0.089 \\
\cline { 3 - 3 } & 1.06 & 0.096 \\
\hline
\end{tabular}

\section{Heave motion analysis}

Figure 6 and 7 present displacement of the tested devices in terms of time series (left) and mean elliptical trajectory of the floater (right); results are shown for the rigid and the flexible devices respectively.

The motion analysis is carried out also in order to estimate the submergence of the floater during the wave cycle and its influence on the pumping mechanism of the device: at each wave cycle, signals of free surface elevation (blue line) and floater vertical displacements (red line) are compared.

All values are recorded at $30 \mathrm{~Hz}$ frequency, calculating the mean value of the submergence.

For both rigid and flexible devices, the tests performed under waves $\mathrm{Cc}$, Tc and Te show same response frequency for the incoming wave and the device displacements. An exception is observed under wave Sc for both the devices. Indeed, in the spectral analysis reported in Figure 8, two main peak frequencies are identified: the first one corresponds to the wave period (i.e. $1 \mathrm{~s}$ ) while the second one (i.e. $2 \mathrm{~s}$ ) is correlated to solicitation of the natural frequency of the device. 
The response signal of the device under this wave seems to be a combination of the natural frequency of the device and the frequency of the incoming wave.

Probably for this reason, in these tests, the spatial trajectory of the device motion does not fit the elliptical shape, as shown for the other waves (Figures 6 and 7, third row).
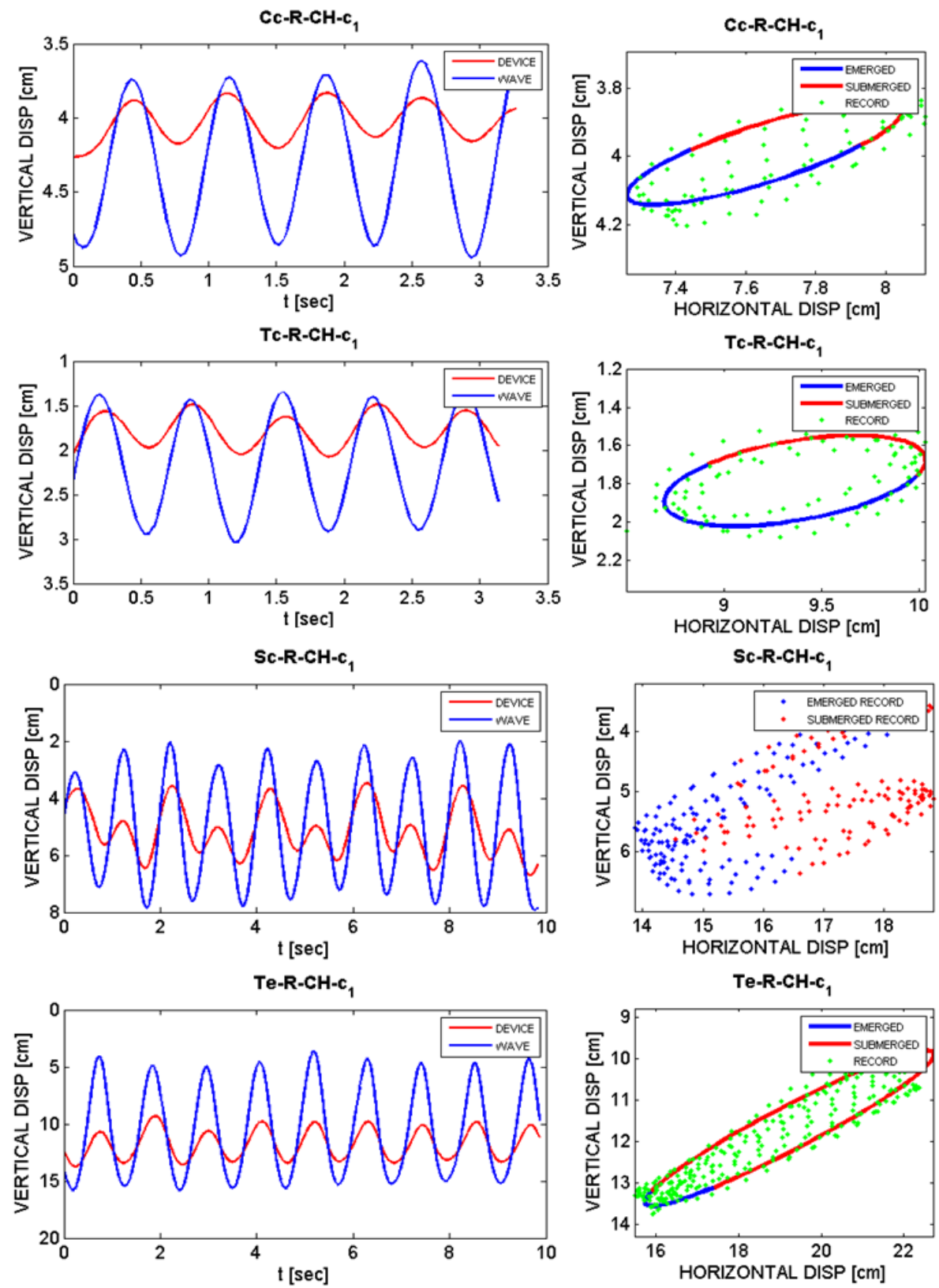

Figure 6. Results for the rigid device: vertical displacement in time (left) and spatial trajectory (right) 



Figure 7. Results for the flexible device: vertical displacement in time (left) and spatial trajectory (right)
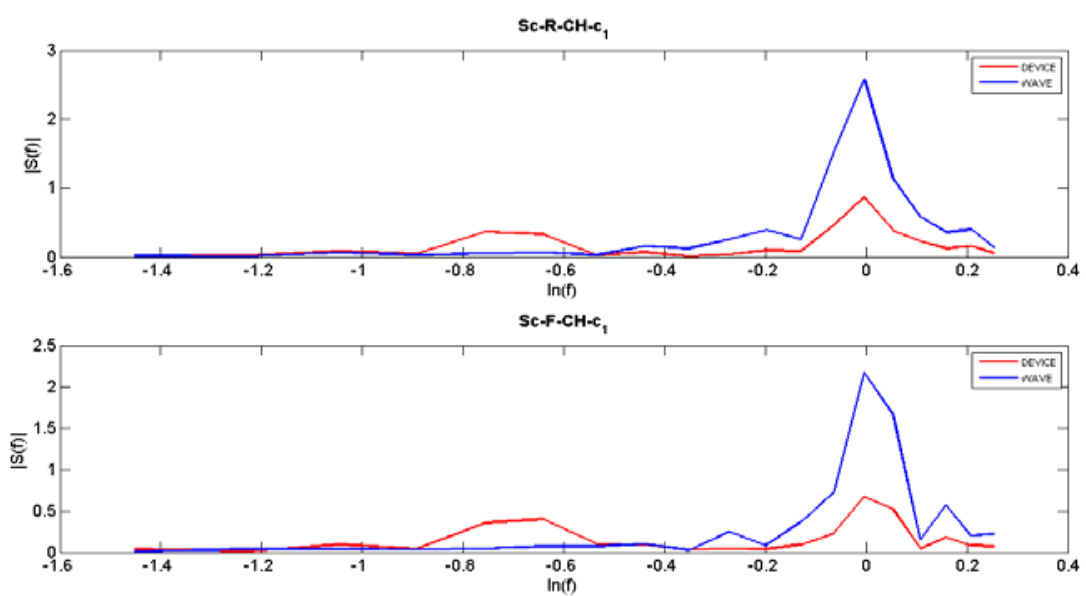

Figure 8. Energy spectrum for the vertical displacement (red) and for the free surface oscillation (blue): rigid (top) and flexible (bottom) devices under wave Sc. 


\section{Velocity field analysis}

A DOP sensor is installed along the pipe axis at a distance approximately equal to $15.00 \mathrm{~cm}$ from the top of the floater. From this level, measurements of the vertical velocity profile inside the tube are collected up to $7.5 \mathrm{~cm}$ of distance: a spatial grid equal to $0.075 \mathrm{~cm}$ and a sampling frequency equal to $52.77 \mathrm{~Hz}$ are imposed. The DOP data allow calculating the time average velocity at each single point of the measured profile.

In the present study, the velocity results come from the average of 2500 values collected in sole point of the grid. To exclude from the analysis the wake effect of the sensor and turbulence caused by overtopping, data collected beyond $7 \mathrm{~cm}$ under the DOP are used to estimate the phase-average velocity. The sensor inherently moves with the floater; in this way, relative velocity is negligible.

The method to estimate flux velocity inside the duct is not robust for the highest waves acting on the flexible device, since the sensor is linked to the floater, but not to the flexible duct; hence, the emitted beam may sometimes measure velocity outside the duct.

Under the lowest wave $(\mathrm{Cc})$, for the flexible device with the higher freeboard $\left(\mathrm{c}_{2}\right)$, no overtopping occurs, while using a lower crest level $\left(\mathrm{c}_{1}\right)$, some overtopping is observed. This is caused by the device movements riding the waves.

For the rigid device, no significant velocity difference is observed with only floater freeboard changes.

Figure 9 shows the relation between the estimated flux velocity and the submergence percentage, revealing that, when overtopping occurs, larger floater freeboard assures downward flux: the optimal value of submergence is found to be equal to $25 \%$.

For higher submergence level (greater than 40\%), corresponding to higher wave conditions (Sc and Te), water is spilled out of the reservoir (velocity is negative); this process is not observed during the waves $\mathrm{Cc}$ and $\mathrm{Tc}$, testifying that the pump mechanism is properly working with calm sea waves, when the maximum vertical stratification often occurs.

In Figure 10, all the higher measured velocities are typically observed for devices moored with the cables. When the vertical displacements are larger than $2 \mathrm{~cm}$, velocity measurements show that the water flux is upwards.



Figure 9. Mean flux velocities inside the device against the percentage of submergence (downward velocity is positive). 

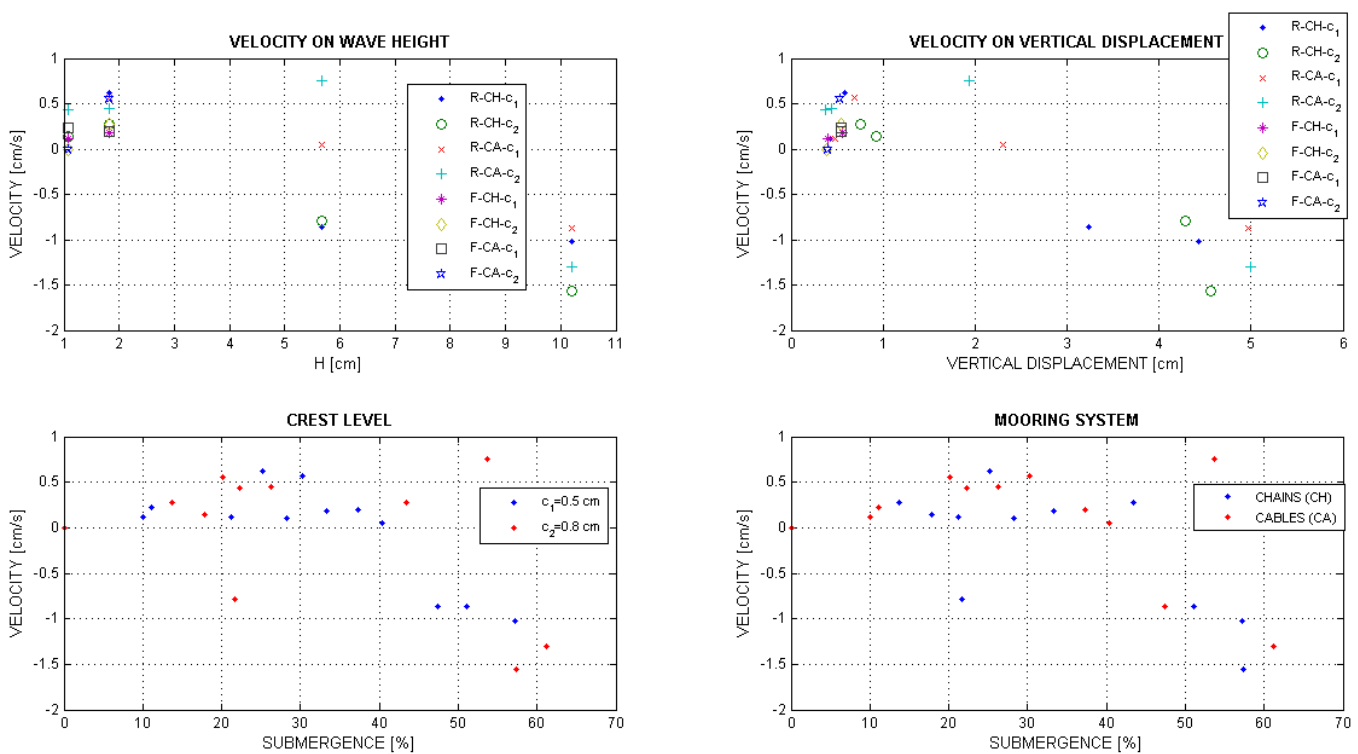

Figure 10. Mean flux velocity inside the device: relation with the wave height, vertical displacement, crest level and mooring systems.

\section{CONCLUSIONS}

A total of 32 tests was carried out in the wave flume of the Laboratory of Hydraulic Engineering at the University of Bologna in order to investigate the efficiency of floating devices aiming to pump oxygen-rich surface water downwards to deep layers.

Rigid and flexible pipes have been tested, together with different mooring systems (chains and cables) and buoyancy levels.

Previously, free oscillation tests have showed that the natural heave period and the damping ratio are largely affected by the mooring systems. The values of the natural periods have been found to be around $1.00 \mathrm{~s}$, with one exception occurring for wave Sc, where the natural period of the device is close to the wave period, probably causing a second main frequency in the oscillation.

The phase-average downward velocity inside the tube has been derived by DOP measurements and the results have been compared for the different mooring systems and wave attacks.

Both devices can pump surface water downwards to deep layer during the condition of maximum stratification (i.e. calm sea), when the flux velocities inside the tube are of the order $0.3 \mathrm{~cm} / \mathrm{sec}$. On the other hand, during highest waves, the devices seem to suck water from the bottom upwards to the surface.

When overtopping occurs, the duration and the degree of submergence have significant effect on the pumping mechanism; wave crest water flows over the floater but not into it in case of excessive level of submergence.

Movements of the floating body, largely dependent on the mooring systems, have a negative influence on the overtopping rate as observed also by Margheritini (2011). Higher heave displacements are usually observed when cables are installed, while higher surge displacements occur when chains are mounted.

For the flexible device, floater emergence is shown to have a leading role in the pumping process: indeed, for the higher freeboard no overtopping is observed during wave $\mathrm{Cc}$. For the rigid device, floater emergence becomes a parameter of lower importance, since the pumping mechanism is more influenced by the vertical displacement.

The mooring system largely affects the movements of both the tested devices and the efficiency of pumping water downwards increases using the cables.

\section{REFERENCES}

Artegiani, A., Bregant, D., Paschini, E., Pinardi, N., Raicich, F., Russo, F. 1996. The Adriatic Sea General Circulation. Part I: Air-Sea Interactions and Water Mass Structure, Journal of Physical Oceanography, 27, pp. 1492-1514. 
Artegiani, A., Bregant, D., Paschini, E., Pinardi, N., Raicich, F., Russo, F. 1996. The Adriatic Sea General Circulation. Part II: Baroclinic Circulation Structure, Journal of Physical Oceanography, 27, 1515-1532.

Boni, L., Pompei, M., Reti, M., 1986. Maree colorate e fioriture algali lungo le coste dell'EmiliaRomagna dal 1982 al 1985 con particolare riguardo alla comparsa di Protogonyaulax tamarensis. Nova Thalassia,8, pp. 237-245.

Boni, L., Ceredi, A., Guerrini, F., Milandri, A., Pistocchi, R., Poletti, R., Pompei, M., 2000. Toxic Protoceratium reticulatum (Peridiniales, Dinophyta) in the north-western Adriatic Sea (Italy). In: Hallegrae, G.M., Blackburn, S.I., Bolch, C.J., Lewis, R.J. (Eds.), Harmful Algal Blooms, Proceedings of the IX International Conference on Harmful Algal Blooms. UNESCO, Paris,137140.

Cattani, O., Vitali, G., 1995. Effetti degli adattamenti biochimici alla carenza di ossigeno degli organismi marini sulle comunita bentoniche di aree eutrofizzate. Il caso dell'Adriatico nordoccidentale. In: Regione Emilia Romagna (Ed.), Proceedings of the Conference on "Evoluzione dello stato trofico in Adriatico: analisi degli interventi attuati e future linee di intervento'. Regione Emilia Romagna, Bologna, pp. 101-112

Czolczynski, K. 2004. On the existence of a stable periodic solution of an impacting oscillator with damping. Chaos, Solitons \& Fractals, 19, pp. $1291-1311$.

Degobbis, D. 1989. Increased eutrophication of the Northern Adriatic Sea. Second Act. Marine Pollution Bulletin, 20, pp. 452-457.

Degobbis, D., Fonda-Umani, S., Franco, P., Malej, A., Precali, R., Smodlaka, N., 1995. Changes in the Northern Adriatic ecosystem and appearance of hypertrophic gelatinous aggregates. The Science of the Total Environment 165, pp. 43-58.

Diaz, R., Solow, A,. 1999. Ecological and economic consequences of hypoxia. Topic2 Report for the integrated assessment on hypoxia in the Gulf of Mexico, US department of commerce, national oceanic and atmospheric administration.

Diaz, R. 2001. Overview of Hypoxia around the World. Journal of Environmental Quality, 30, pp.275281.

European Environmental Agency, 1994. European rivers and lakes. Environmental Monographs 1, Copenhagen.

Fofono, N. P., and R. C. Millard, 1983. Algorithms for computations of fundamental properties of seawater. Unesco Technical Papers in Marine Science No. 44,53pp

Giordani, P., Hammond, D.E., Berelson, W.M., Montanari, G., Poletti, R., Milandri, A., Frignani, M., Langone, L., Ravaioli, M., Rovatti, G., Rabbi, E., 1992. Benthic fluxes and nutrient budget for sediments in the Northern Adriatic Sea: burial and recycling efficiencies. In: Vollenweider, R.A., Marchetti, R., Viviani, R. (Eds.), Marine Coastal Eutrophication. Elsevier, Amsterdam, pp. 25275.

Marchetti, R., Provini, A., Crosa, G., 1989. Nutrient load carried by the River Po into the Adriatic Sea, 1968e87. Marine Pollution Bulletin, 20, pp. 168-172.

Margheritini, L,. Claeson, L,. 2011. An innovative way of utilizing wave energy to counteract eutrophication and hypoxia. Proceedings of the 9th European Wave and Tidal Conference, Southampton, EWTEC 2011.

Sangiorgi, F., Donders, T., 2003. Reconstructing 150 years of eutrophication in the north-western Adriatic Sea (Italy) using dinoflagellate cysts, pollen and spores, Estuarine, Coastal and Shelf Science, 60, pp. 69-79.

Smayda, T., 1990. Novel and nuisance phytoplankton blooms in the sea: evidence for a global epidemic. In: Graneli, E., Sunstrøm, B.,Edler, L., Anderson, D.A. (Eds.), Toxic Marine Phytoplankton. Elsevier, New York, pp. 29-40.

Viviani, R., 1992. Eutrophication, marine biotoxins, human health. In: Vollenweider, R.A., Marchetti, R., Viviani, R. (Eds.), Marine Coastal Eutrophication. Elsevier, Amsterdam, pp. 631-662.

Vollenweider, R.A., Rinaldi, A., Montanari, G., 1992. Eutrophication, structure and dynamics of a marine coastal system: results of a ten years monitoring along the Emilia-Romagna coast (Northwest Adriatic Sea). In: Vollenweider, R.A., Marchetti, R., Viviani, R. (Eds.), Marine Coastal Eutrophication. Elsevier, Amsterdam, pp. 63-106.

Zavatarelli, M., Raicich, F., Bregant, D., Russo, A., Artegiani, A. 1998. Climatological biogeochemical characteristics of the Adriatic Sea. Journal of Marine Systems, 18, pp. 227-263. 